\title{
Hafnium Oxide as Efficient Material for a New Generation Dielectric
}

\author{
A.P. Mukhachov ${ }^{a}$, O.A. Kharitonova ${ }^{b, *}$ And O.A. Terentieva ${ }^{b}$ \\ ${ }^{a}$ Chemical Technology of AISU, Kamyanske, Ukraine \\ ${ }^{b}$ Dniprodzerzhinsk State Technical University, 2 Dniprobudivska Str., 51900 Kamyanske, Ukraine
}

\begin{abstract}
In the early 2000-ies, world leaders in the field of computer engineering, such companies as IBM, Intel and Samsung Electronics announced the development of a new technology for the production of boards based on multilayer films $\mathrm{HfO}_{2}-\mathrm{Al}_{2} \mathrm{O}_{3}$ on a silicon pad using the method of atomic layer deposition. The board has a high dielectric constant value thus making it possible to produce smaller transistors with increased operational speed, to reduce leakage current and electric energy consumption. It has been known that hafnium oxide is used in the production of optical devices, resistors, electronic ceramics, neutron absorption compositions, and catalysts. High purity of material is one of key conditions for its application. As source material, hafnium concentrate was used that was enriched to $10 \%$ in the form of $\mathrm{K}_{2}(\mathrm{ZrHf}) \mathrm{F}_{6}$ salt - the product of fractional crystallization of zirconium and hafnium fluorides in the production of zirconium for nuclear applications. Another source material is a $\mathrm{HFO}_{2}$ commercial-grade hafnium oxide produced at Vilnogorsk Mining and Smelting Works. Key process stages are fusion with alkali at a temperature of $800^{\circ} \mathrm{C}$, dissolution in nitric acid and extraction. The impurities content of resultant hafnium re-extract is $10-5 \%$ (mass). The prime objective of the process technology is the preservation of hafnium purity in its oxide production, which is attained by the application of materials and equipment items having a high corrosion resistance, such as stainless steel, crucibles made of high-purity silicon, reaction vessels made of zirconium and fluoroplastic. Centrifugal extractors allow the key critical process of hafnium extraction purification to be sufficiently effective, resulting in obtaining the product of a required $99.99 \%$ purity. Physical properties of hafnium oxide are presented in sufficient detail in. Hafnium oxide can by produced using various methods to be selected based on the requirements to product quality, process efficiency and cost considerations.
\end{abstract}

DOI: 10.12693/APhysPolA.133.778

PACS/topics: Hafnium oxide, extraction, phase, dielectric, centrifugal extractors, extractant

\section{Introduction}

High-purity oxide of hafnium, is used in the new technology boards based on multilayer films $\mathrm{HfO}_{2}-\mathrm{Al}_{2} \mathrm{O}_{3}$ on a silicon substrate by the method of deposition of atomic layers (ALD) [1]. The film has a high value of the dielectric constant, which allows to reduce the size of transistors to increase the speed of operation to reduce leakage current and power consumption. It is known the use of hafnium oxide in the manufacture of optics, resistors, electronic ceramic, the neutron absorbing compositions of the catalysts. One of the main conditions of its application is high purity material. The raw materials used in the mineral zircon, containing $50 \%$ zirconium and $2.0 \%$ of hafnium. Zirconium and hafnium are chemical analogues, but nuclear opponents. As materials, they are of practical value at high purity and the content of the basic substance is not less than $99.9 \%$. Compounds of hafnium can only be obtained after passing the allocation of high purity zirconium for nuclear applications. The content of zirconium in the hafnium ranges from $4.0 \%$ to $50 \mathrm{ppm}$, depending on customer requirements and applications. The content of impurities should be at $50 \mathrm{ppm}$ to the physical properties of hafnium oxide was the highest. In

*corresponding author; e-mail: eah@ukr.net the processing of zircon can be a variety of intermediate compounds of hafnium, which must be cleaned from impurities. All the requirements on the quality of the oxides of zirconium and hafnium is only responsible extraction technology, which has found wide application in the industry of nuclear-pure materials.

Hydrochloric, sulfuric, and nitric acids are used for the extraction of $\mathrm{Zr}$ and Hf. All of the reagents were only nitrate compounds utilized in the manufacture of fertilizers. Nitrate compounds of $\mathrm{Zr}$ and $\mathrm{Hf}$ are in stable condition at $\mathrm{a} \mathrm{HNO}_{3}$ concentration not less than $400.0 \mathrm{~g} / \mathrm{l}$. However, destruction of tributyl phosphate (TBP extractant) occurs with the formation of mono and dibutylphosphoric acids, which remove the extraction process from equilibrium, forming undivided emulsions, disturbing the process condition and the completeness of phase separation [2].

The combination of the extraction technology of separation and purification of $\mathrm{Zr}$ and $\mathrm{Hf}$ with effective centrifugal equipment made of special steel resistant in a nitric acid medium with the use of high-purity reagents made it possible to successfully combine high-purity compounds of these metals in a single technological cycle.

The aim of this work was to develop and optimize processes for extraction separation of zirconium and hafnium, the creation of industrial technology of obtaining high purity oxide of hafnium, opening up new areas of applications in industry. 


\section{The methodology of the industrial experiment}

The Zircon mineral was sintered with ${ }_{2} \mathrm{SiF}_{6}$ and after fractional crystallization of the double fluoride salts of $\mathrm{Zr}$ and Hf, $6-10 \%$ of hafnium concentrate was obtained. It was washed from the fluorine-ion with hot alkali solution. Hydroxide of the metals sum was obtained and dissolved in $45 \%$ nitric acid. The nitric acid solution with an acidity of $420 \pm 20 \mathrm{~g} / 1$ was directed to the extraction process using $70 \%$ tributyl phosphate and hydrocarbons. The zirconium extract was directed to zirconium production, and a 40-90\% hafnium re-extract was subjected to repeated extraction treatment on CET-125 extractors (brand centrifugal extractor, rotor diameter $125 \mathrm{~mm}$ ) to isolate the hafnium compounds and utilize zirconium. The $100 \%$ hafnium concentrate reacted with phthalic acid to form a loose precipitate that was washed with water, dried at $150^{\circ} \mathrm{C}$, calcined at $850^{\circ} \mathrm{C}$ to hafnium oxide.

\section{Results of industrial experiment}

Dissolution of the hydroxide of the amount of $\mathrm{Zr}$ and Hf in nitric acid is described by reaction (1) [3]:

$$
\begin{gathered}
\mathrm{Hf}(\mathrm{Zr}) \mathrm{O}(\mathrm{OH})_{2}+2 \mathrm{HNO}_{3}= \\
\mathrm{Zr}(\mathrm{Hf}) \mathrm{O}\left(\mathrm{NO}_{3}\right)_{2}+2 \mathrm{H}_{2} \mathrm{O} .
\end{gathered}
$$

As the electrolyte there can be used sodium nitrate up to $100 \mathrm{~g} / \mathrm{l}$. High acidity of the solution was required to prevent polymerization of the solution in which insoluble precipitates fall out. For the extraction process has been tested centrifugal extractor different designs, the best results in quality and productivity was obtained in extractors of the type CET-125.

The versatility of the selected centrifugal extractors is allowed to put into practice all the processes of extraction, stripping, washing, neutralization, and acidification of the extractant. Compared to mixer-settler reactors, the use of centrifugal fields allowed 60 times to reduce the required time of delamination of the emulsion, 10 times to reduce the contact time of the phases in the mixing chamber, with the same efficiency of mass transfer due to mixing intensity. As a result, the concentration of hydrolysis products of TBP decreased by 5 times, which is hydrolyzed by the action of nitric acid with the formation of di-, monobutylphosphoric and phosphoric acids by the reaction [4]:

$$
\begin{aligned}
& \left(\mathrm{C}_{4} \mathrm{H}_{9}\right)_{3} \mathrm{PO}_{4}+\mathrm{H}_{2} \mathrm{O} \rightarrow \\
& \mathrm{C}_{4} \mathrm{H}_{9} \mathrm{OH}+\left(\mathrm{C}_{4} \mathrm{H}_{9}\right)_{2} \mathrm{P}(\mathrm{OH}) \mathrm{O}_{3}, \\
& \left(\mathrm{C}_{4} \mathrm{H}_{9}\right)_{2} \mathrm{P}(\mathrm{OH}) \mathrm{O}_{3}+\mathrm{H}_{2} \mathrm{O} \rightarrow \\
& \mathrm{C}_{4} \mathrm{H}_{9} \mathrm{OH}+\mathrm{C}_{4} \mathrm{H}_{9} \mathrm{P}(\mathrm{OH})_{2} \mathrm{O}_{3}, \\
& \left(\mathrm{C}_{4} \mathrm{H}_{9}\right) \mathrm{P}(\mathrm{OH})_{2} \mathrm{O}_{3}+\mathrm{H}_{2} \mathrm{O} \rightarrow \\
& \mathrm{C}_{4} \mathrm{H}_{9} \mathrm{OH}+\mathrm{H}_{3} \mathrm{PO}_{4} .
\end{aligned}
$$

Regardless of the composition of the initial electrolyte $\left(\mathrm{HNO}_{3}=0.2-6 \mathrm{~mol} / \mathrm{l}, \mathrm{Zr}(\mathrm{Hf})=50-600 \mathrm{mg} / \mathrm{l}\right)$ of an or- ganic solution of dibutylphosphoric acid (DBPA) $=0.5-$ $1.6 \mathrm{~g} / 1$, DBPK reacts with the microquantity $\mathrm{Zr}$.

The sediment is insoluble in water, aqueous solutions of acids, as well as in the TBP-diluent system, which leads to clogging of the sediments of technological equipment and the appearance of difficultly dissolving emulsions [5].

As a rule, soda washing is used to purify TBP from hydrolysis products, however, it does not solve the problem

The concentration of the sediment reaches $3 \mathrm{~g} / 1$, which leads to the extraction of the extractor from the regime. The introduction of the fixed element in the hydraulic seal allowed the extraction process to be carried out while maintaining the hydrodynamic regime. This increased the uptime of the system to $15,000 \mathrm{~h}$. Along with the physical capture of sediment needed to find and method of its complete dissolution, as it can accumulate in the extractors. Analysis of the sediment showed that TBP - solvent HNO3, the precipitate is formed only of the composition $\mathrm{Zr}(\mathrm{Hf})\left(\mathrm{NO}_{3}\right)_{2} \cdot\left(\left(\mathrm{C}_{4} \mathrm{H}_{9}\right)_{2} \cdot \mathrm{PO}_{3} \mathrm{OH}\right)_{2}$.

The influence of reagents on transition metals from the sediment into the solution was investigated (Table I).

TABLE I

The degree of destruction of dibutylphosphate of zirconium (hafnium), depending on the composition of the aqueous phase.

\begin{tabular}{c|c|c|c}
\hline \hline No. & Composition & Contact [min] & Destruction [\%] \\
\hline 1 & $\mathrm{NaOH}$ & 60 & 1 \\
2 & $\mathrm{HNO}_{3}$ (conc.) & 60 & - \\
3 & $\mathrm{NaOH}+\mathrm{H}_{2} \mathrm{O}_{2}$ & 2 & 100 \\
4 & $\mathrm{NH}_{4} \mathrm{OH}+\mathrm{H}_{2} \mathrm{O}_{2}$ & 60 & 1.0 \\
5 & $\mathrm{H}_{2} \mathrm{O}\left(t^{\circ}\right)$ & 180 & -
\end{tabular}

The degree of destruction of zirconium dibutyl phosphate was determined by the formula

$$
\gamma[\%]=100 \%-\frac{m_{\mathrm{Zr}}-C_{\mathrm{Zr}}}{m_{\mathrm{Zr}}} \cdot 100 \%,
$$

where $\gamma$ - degree of sediment destruction [\%], $m_{\mathrm{Zr}}$ - the content of zirconium in the sediment, $C_{\mathrm{Zr}}$ is the content of zirconium in solution.

It can be seen from the table that completely dibutyl phosphate of zirconium is destroyed in an aqueous solution $\mathrm{NaOH}$ and $\mathrm{H}_{2} \mathrm{O}_{2}$.

\section{Selection of optimal dissolution conditions}

Dissolution was carried out at room temperature $t=$ $20-25^{\circ} \mathrm{C}$. The dependence of the degree of dissolution of the sediment on the concentration of alkali in a solution at a constant value for $5 \mathrm{~min}$ is shown in Fig. 1 .

It can be seen that as the concentration in the solution increases, the degree of dissolution of the precipitate increases, but from the kinetic dependences (Figs. 2, 3) it can be concluded that the rate of dissolution (destruction) of the precipitate depends not on the concentration of $\mathrm{NaOH}$ but on the ratio $\mathrm{NaOH}$ and $\mathrm{H}_{2} \mathrm{O}_{2}$ in solution. 


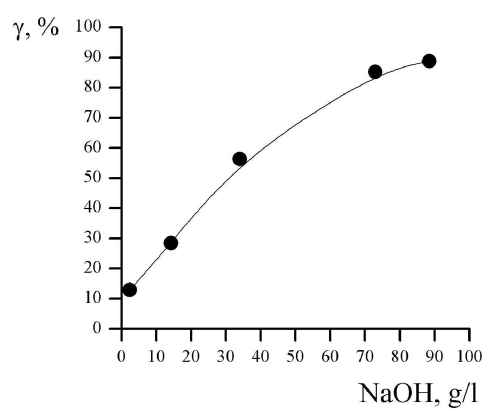

Fig. 1. The degree of dissolution of the precipitate of zirconium dibutyl phosphate (hafnium).

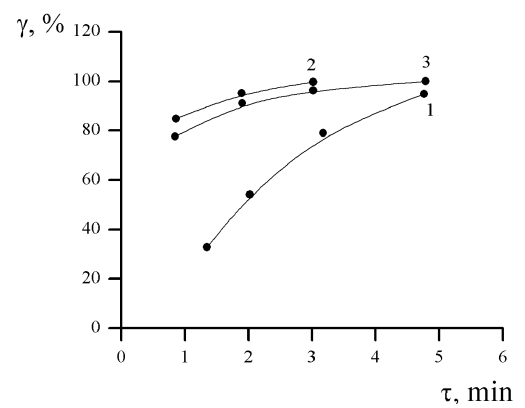

Fig. 2. Degree of destruction of zirconium dibutyl phosphate as a function of the duration of phase contact, for different values $[\mathrm{NaOH}]=30 \mathrm{~g} / 1-1$, $[\mathrm{NaOH}]=50 \mathrm{~g} / 1-2,[\mathrm{NaOH}]=100 \mathrm{~g} / 1-3$, where $\left[\mathrm{H}_{2} \mathrm{O}_{2}\right]=$ const $=21 \mathrm{~g} / 1$.

The effect of the hydrogen peroxide concentration in the mixture on the precipitate dissolution is shown in Fig. 4.

Investigation of the conditions for the destruction of the precipitate as a function of the molar ratios showed that with a $\frac{M_{\mathrm{NaOH}}}{M_{\mathrm{H}_{2} \mathrm{O}_{2}}}=2$ maximum solubility of the precipitate reaches $10 \mathrm{~g} / 1$ for the metal. In this respect, the precipitate did not drop out for a long time. The use of

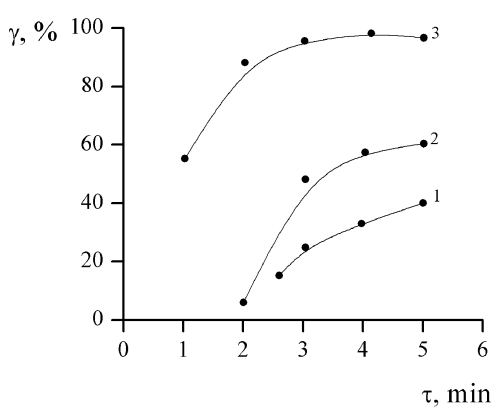

Fig. 3. Degree of destruction of zirconium dibutyl phosphate depending on the duration of phase contact, for different values, where $[\mathrm{NaOH}]=30 \mathrm{~g} / 1-$ $1,[\mathrm{NaOH}]=50 \mathrm{~g} / 1-2,[\mathrm{NaOH}]=100 \mathrm{~g} / 1-3$, where $\left[\mathrm{H}_{2} \mathrm{O}_{2}\right]=$ const $=50 \mathrm{~g} / \mathrm{l}$.

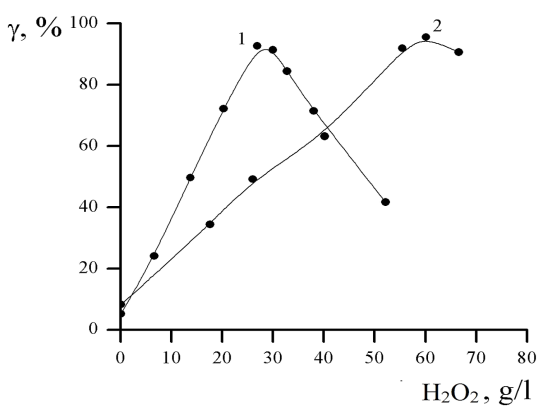

Fig. 4. The degree of dissolution of the precipitate of zirconium dibutyl phosphate (hafnium) as a function of the concentration in the solution, $\tau=5 \mathrm{~min}$.

alkaline-peroxide electrolyte made it possible to create a two-phase liquid-liquid system during purification of the turnaround extractant, dissolve the sediment from the inner surface and return the metals to the cycle. As a result of the studies, an efficient instrumentation scheme was developed for obtaining high-purity hafnium oxide.

The developed technology made it possible to purify hafnium to an impurity content of less than $50 \mathrm{ppm}$ and obtain a standard sample of $\mathrm{HfO}_{2}$.

\section{Conclusions}

1. On the basis of the results obtained, an effective instrumentation-technological scheme for the processing of zirconium has been developed, which makes it possible to obtain zirconium and hafnium compounds containing $99.95 \%$ of the basic substance.

2. The extraction method for obtaining high-purity hafnium compounds from nitric acid media allows reducing the impurity content to $50 \mathrm{ppm}$.

3. Centrifugal extractors such as CET-125 provide the minimum phase contact time, minimum losses of electrolyte with organic phase, effective purification of the turnaround extractant, high degree of separation of hafnium and zirconium in a single technological cycle.

4. As the working solution for cleaning the extractant, an alkaline-peroxide solution with a mole ratio of $\mathrm{NaOH}: \mathrm{H}_{2} \mathrm{O}_{2}=2$.

\section{References}

[1] G. Reznik, Int. Rev. 48 12, 86 (2002).

[2] G.I. Kuznetsov, A.A. Pushkov, A.V. Kosogorov, Centrifugal Extractors Tsentrak, RCTU them. M. Mendeleyev, Moscow 2000.

[3] I.A. Sheka, K.F. Karlysheva, Chemistry of Hafnium, Naukova dumka, Kiev 1973, p. 154.

[4] M. Benedikt, T. Pigford, Chemical Technology of Nuclear Materials (in Russian, translated from English), Izd-vo glavnogo upravleniya po ispol'zovaniyu atomnoy energii pri sovete ministrov USSR, Moscow 1960 pp. $295,333$.

[5] A.P. Mukhachev, et al., Copyright certificate No. 1655905 USSR Method of removing sediment of dibutyl phosphates of zirconium and hafnium from 15.02.1991. 